\title{
Use of unmanned aerial systems for assessing the dynamics of hazardous engineering and geocryological processes on linear facilities
}

\author{
Nikolay Grib ${ }^{1,2}$ *, Andrey Melnikov ${ }^{3}$, Galina Grib ${ }^{1}$ and Andrey Kachaev ${ }^{1}$ \\ ${ }^{1}$ Technical Institute (branch) of the Ammosov Northeast Federal University, 678960, Neryungri, \\ Russian Federation \\ ${ }^{2}$ Academy of Sciences of the Republic of Sakha (Yakutia), 677007, Yakutsk, Russian Federation \\ ${ }^{3}$ Melnikov Permafrost Institute of the Siberian Branch of the Russian Academy of Science, 678907, \\ Yakutsk, Russian Federation
}

\begin{abstract}
Linear engineering facilities, such as gas transportation systems, extend from 30 to 500 metres in width and several hundred kilometres in length. Such routes pass through areas characterized by sufficiently diverse engineering, geological, geocryological and seismotectonic conditions. The safe and reliable functioning of gas transportation systems is ensured by their regular monitoring to prevent the development of hazardous exogenous geological processes. In particular, when monitoring ice formation, the greatest efficiency can be achieved by using unmanned aerial vehicles for low-altitude aerial surveys. In this research, remote sensing methods based on unmanned technologies were applied to assess the aufeis hazard in a section of the Power of Siberia gas pipeline in South Yakutia. The authors' successful experience of using unmanned systems during an aeromagnetic exploration of iron ore deposits in South Yakutia was also considered. A series of studies, including georadar and electrical exploration profiling, as well as thermal imaging and high-resolution aerial photography by an aerial complex, was conducted to assess the dynamics of ice development over time in the area under study and to establish the signs of a developing hazardous process.
\end{abstract}

Keywords: linear facilities, aufeis, unmanned aerial vehicle, thermal imaging, aerial photography.

\section{Introduction}

In South Yakutia, a section of the Power of Siberia gas transmission system has been put into operation. Previous research highlighted the complex engineering and geological conditions for the passage of the route in this geographical area [1-6]. Due to the limited volume, this article aims to present only selected data on the monitoring of hazardous exogenous geological processes developing along the route of the main gas pipeline, in particular, ice formation processes. Data on the location of an icing and the nature of its development

* Corresponding author: grib@nfygu.ru 
provide additional information on the composition and structure of the permafrost zone. In addition, this information is important for revealing the formation patterns and dynamics of groundwater. The use of ice as an indirect indicator allows the geological, structural and seismotectonic characteristics of the area under study to be elucidated [7-9].

\section{Research methods}

Considering the remote geographical location of the area under study, which made it difficult to organize investigations of ice distribution, as well as the scale and dynamics of icing processes, the monitoring of aufeis was carried out by low-altitude aerial surveys using unmanned aerial vehicles (UAVs) [10-12]. The prospects for such surveys became apparent at the end of the last century. However, despite the rapid development of the UAV market, such technologies are still rarely used in Russian geological practice.

Relying on the authors' successful experience in using unmanned systems during aeromagnetic exploration, including the studies of iron ore deposits in South Yakutia described in [13-20], remote sensing methods using unmanned technologies were used to assess the aufeis hazard at an individual section of the Power of Siberia gas pipeline in South Yakutia. The research works included georadiolocation and electrical survey profiling, thermal imaging and high-resolution aerial photography (up to $0.3 \mathrm{~cm} /$ pixel) by a Geoscan401 flight complex.

Flights across the study area by a Geoscan- 401 complex were carried out at an altitude of 50 meters, with forward overlap of images $80 \%$ and lateral overlap of $90 \%$. The distance between the profiles comprised $20 \mathrm{~m}$. The obtained photogrammetry data were processed in the Agisoft Photoscan Professional software.

The as-obtained information was used to solve the following research tasks:

- $\quad$ to study the dynamics of ice development;

- $\quad$ to identify talik zones in the rocks of the base of the ice body;

- to identify frozen rock zones, potentially dangerous due to the possibility of frost mound formation;

- $\quad$ to determine the main feeding sources of the icing.

\section{Results and discussion}

The orthophotomaps obtained after processing the data gathered by UAV were used for constructing a comprehensive interpretation of geophysical data and calculating the area of icing. Orthophotomaps with the results of thermal imaging made it possible to establish fundamentally important features of ice development.

\subsection{Dynamics of ice development}

Fig.1 (a-d) demonstrates orthophotomaps of the monitored area with calculations of the icing area. It should be noted that, at the current stage of the study, the aufeis was surveyed within 500 meters upstream and downstream from the pipeline crossing the river. The areas of ice were calculated for this particular area according to photogrammetry data processed in the Agisoft Photoscan Professional software. The values of ice areas are presented in Table 1. 
Table 1. Ice area by observation period

\begin{tabular}{|c|c|c|}
\hline Observation date & Ice area, $\mathrm{m}^{2}$ & Increase for the period, \% \\
\hline 02.02 .2018 & 127963 & 38.5 \\
\hline 02.03 .2018 & 177264 & 32.3 \\
\hline 14.04 .2018 & 234463 & -50.0 \\
\hline 06.06 .2018 & 117124 & \\
\hline
\end{tabular}

\subsection{Determination of the main feeding sources of the aufeis}

Fig. 2 shows an orthophotomap (survey carried out on 03/06/2018), combined with a thermal image.

a)
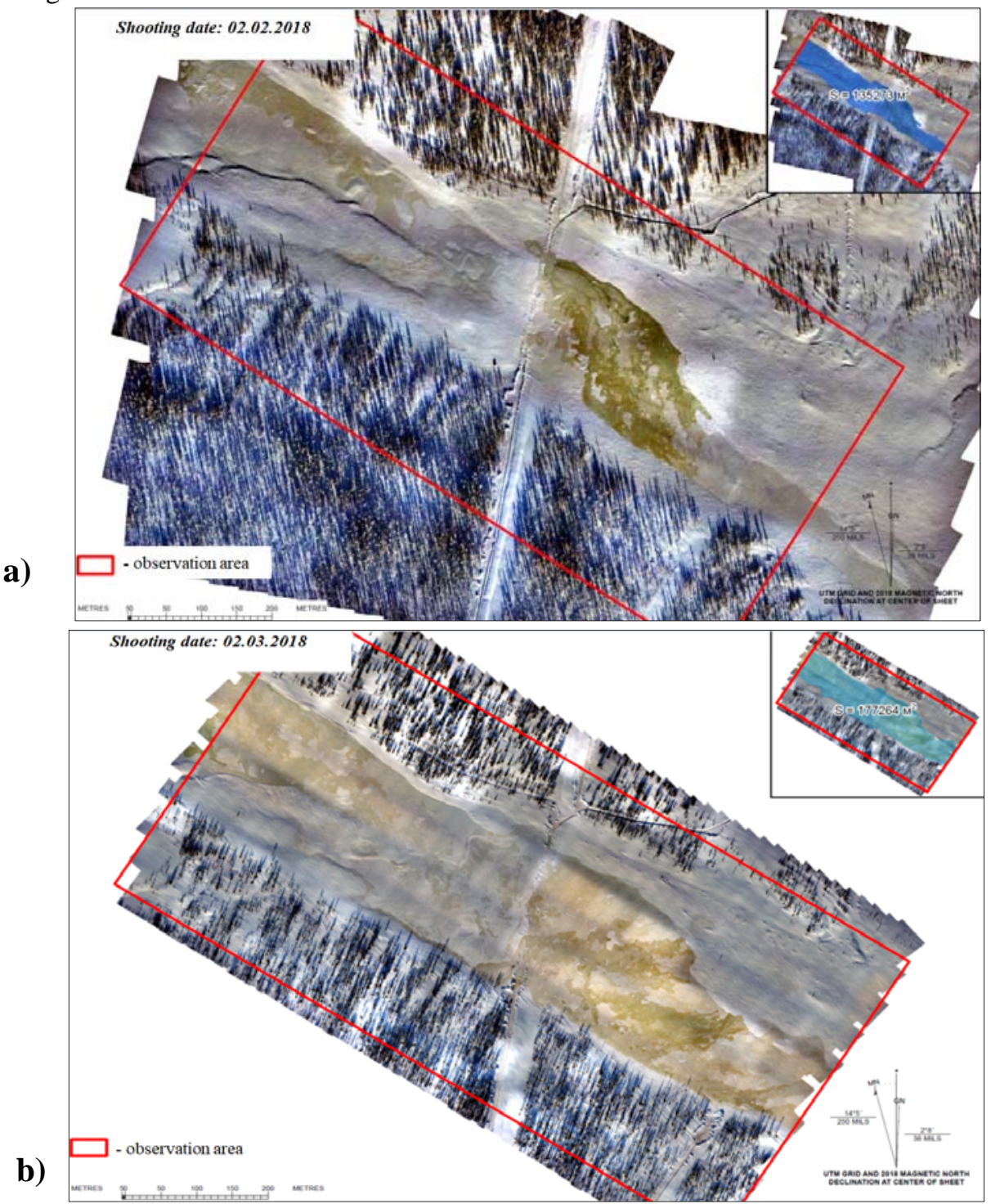

Fig. 1. Orthophotomaps of the monitored site (marked with a red outline) with the calculation of the area of ice by observation periods: $\mathrm{a}-02.02 .2018$; $\mathrm{b}-02.03 .2018$. 
c)
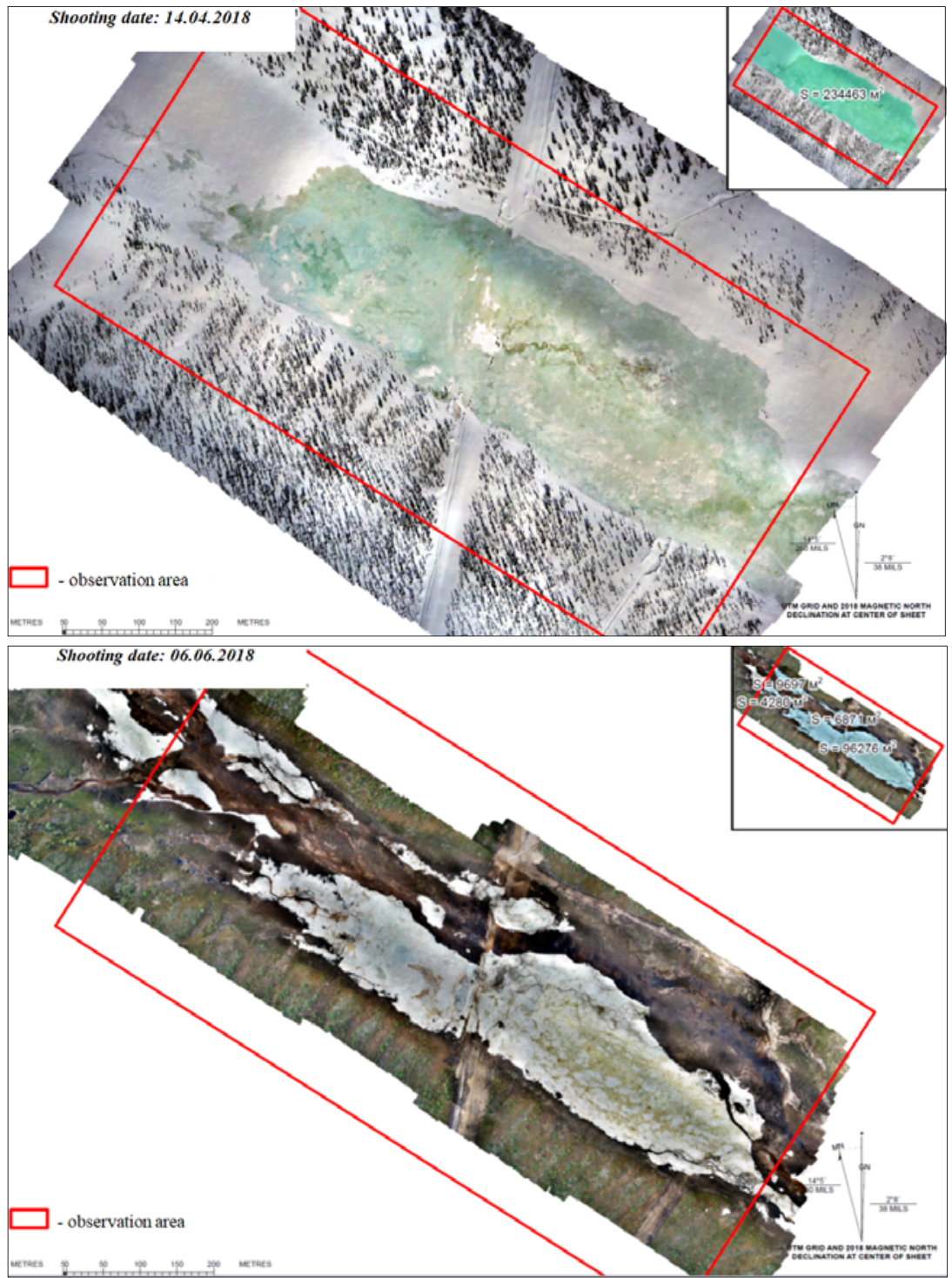

Fig. 1 (continued). Orthophotomaps of the monitored site (marked with a red outline) with the calculation of the ice area by observation periods: c - 14.04.2018; $d-06.06 .2018$.

In Figure 1, high-temperature intervals are highlighted in red. The difference between the deepest red and the deepest blue shade is $30^{\circ} \mathrm{C}$. Alongside an exploded hydrolaccolith (a bright red spot in the image), intervals of elevated temperatures along the watercourse edge are clearly visible. Considering that the strip of elevated temperatures is located on the northeastern slope, it is possible to reliably relate the elevated temperatures in this interval to the presence of an inflow of ground slope waters into the area of ice formation.

The bright red spot of hydrolaccolith on a thermal image deserves special attention. Fig. 3 shows the time sequence of aerial photographs taken on 02.02.2018, 02.03.2018 and 06.03.2018. The fourth part of the figure is a thermal image taken on March 06, 2018. The figure demonstrates the rapidity of the hydrolaccolith development process: although almost no signs of a dangerous process were noted in February and on March 02, the process had already entered its terminal stage on March 06. It was the thermal image that made it possible to confidently identify the newly formed structure. 


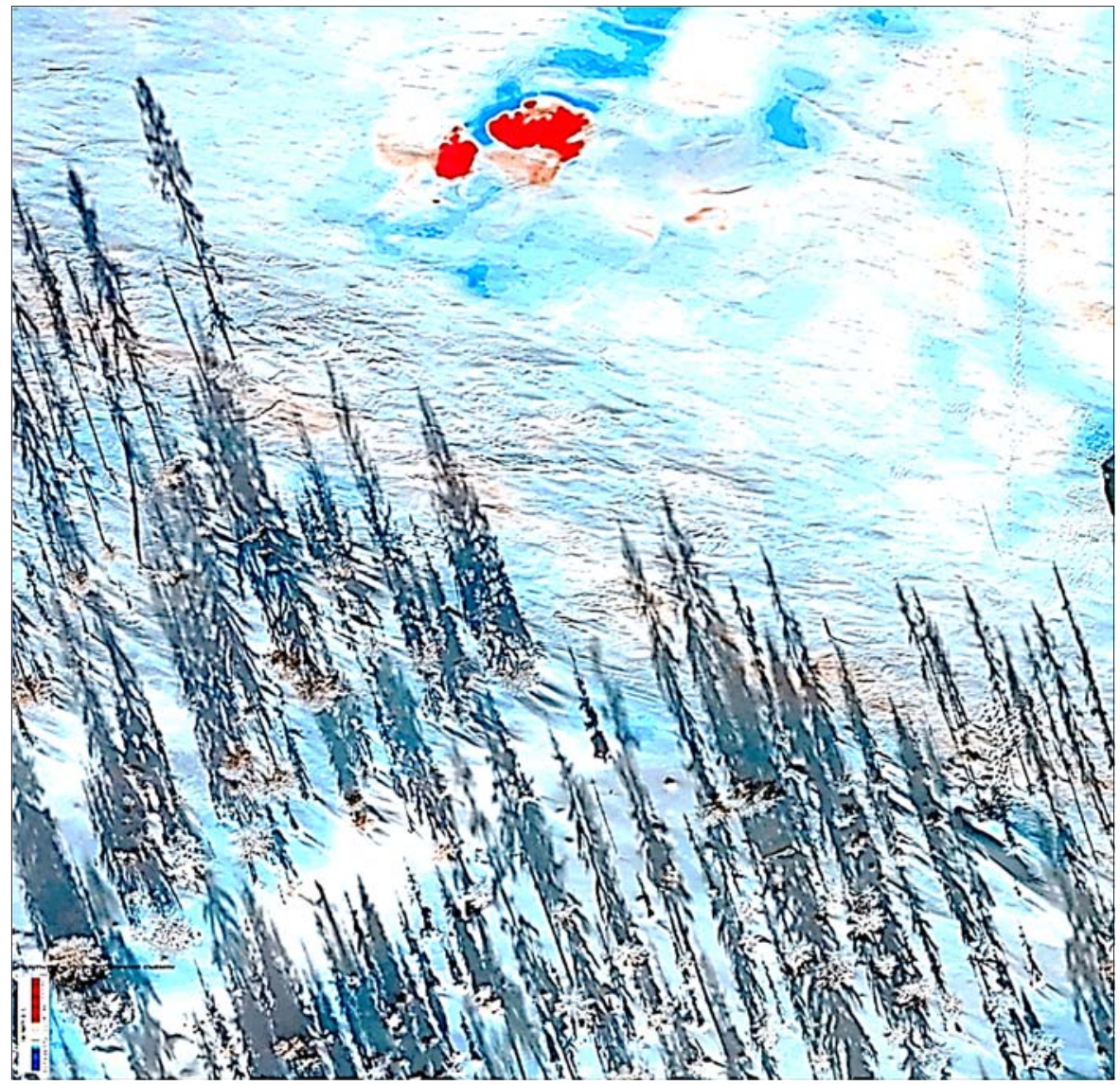

Fig. 2. Thermal imaging combined with an orthophotomap.

One of the advantages of thermal imaging is the possibility of identifying water inflow intervals feeding the icing quite reliably. Fig. 4 shows the water inflow intervals identified over the observation period. Disjunctive diclocations are shown on the same map. There is a clear correlation between the spatial position of water inflows and disjunctive dislocations. Although the images of water inflows during the cold period were distinguished by higher temperatures, the June image clearly marked the pathways of slope waters by lowtemperature anomalies.

\section{Conclusions}

The conducted analysis of the causes driving the dynamics of icing morphometric parameters, which were established from the data collected via remote sensing, allowed the dynamics of ice formation to be investigated. In addition, the key signs of the development of dangerous processes, namely the formation of hydrolaccolith, were determined. The localized outflows of ice-forming waters correlate with the spatial position of tectonic faults in the monitored area. The results of thermal imaging confirmed the reliability of the presented method. 


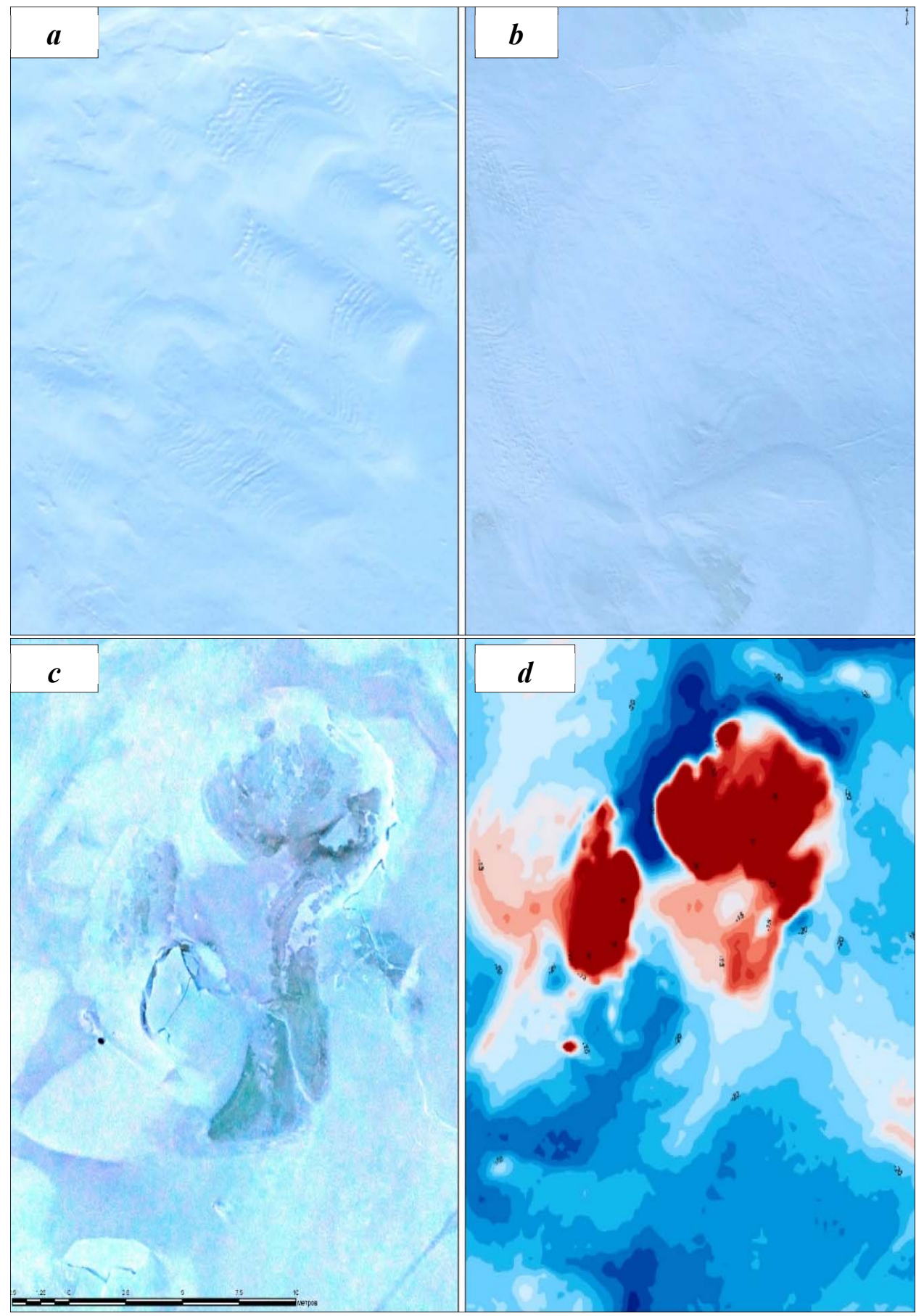

Fig. 3. Hydrolaccolith development in the monitored area the state of the surface of the site: $a$ - midFebruary of 2018; $b-02.03 .2018$; $c$ - 06.03.2018; - thermal image of the site as of 06.03.2018 


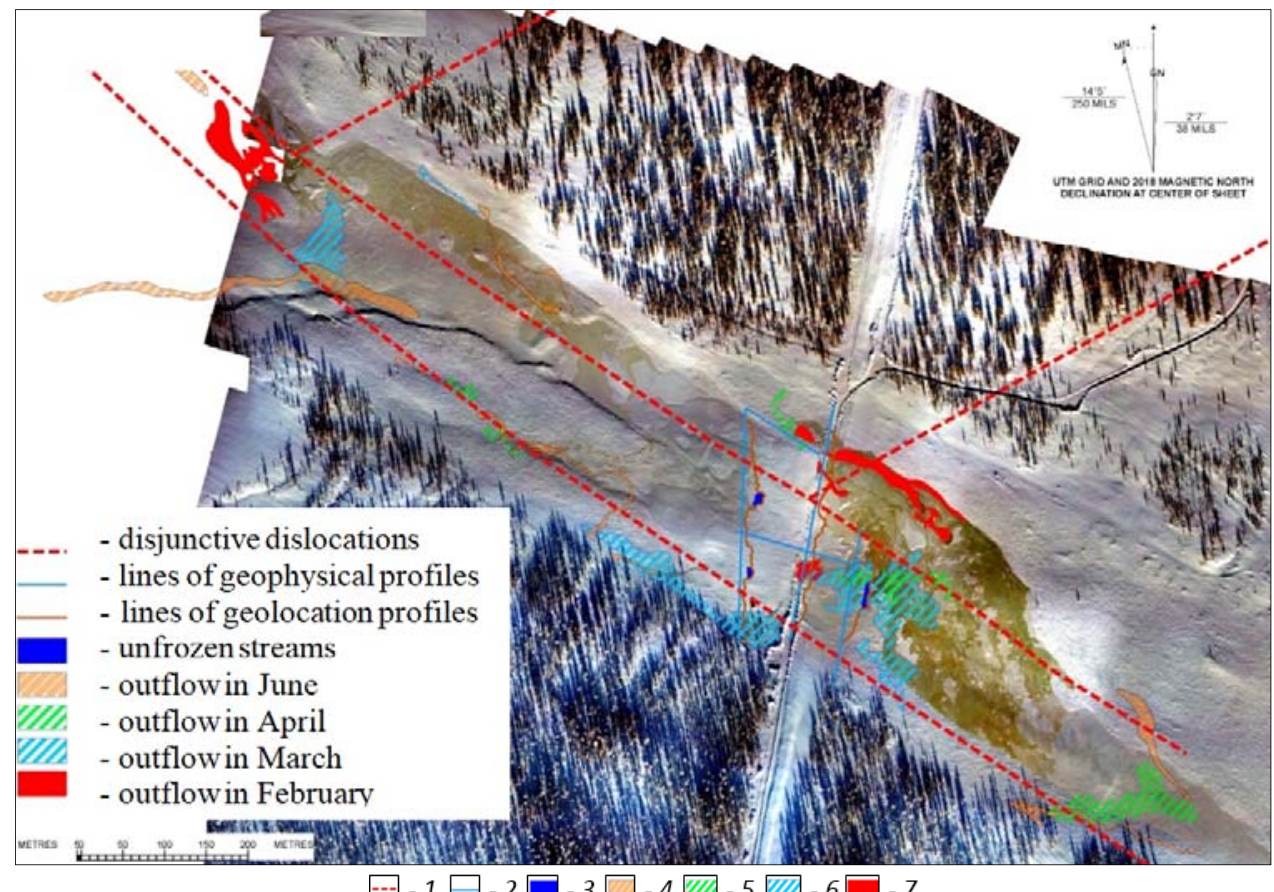

Fig. 4. Localization of ice-feeding groundwater flows

1 - disjunctive dislocations, 2 - lines of geophysical profiles, 3 - unfrozen streams, 4 - outflow in June, 5 - outflow in April, 6 - outflow in March, 7 - outflow in February.

\section{References}

1. M. N. Zheleznyak, S. I. Serikov, M. M. Shatz, Perm J. Pet. Min. Eng., 17, 3, 189 (2018)

2. N. A. Nikolaeva, N. P. Slepcova, L. S. Strekalovskaya, Estestv. i tekhn. Nauki, 114, 12, 146 (2017)

3. A. F. Suhorukova, Interekspo Geo-Sibir', 1, 32 (2018)

4. A. A. Andreev, Vestnik magistratury, I, 3, 54, 22 (2016)

5. A. E. Melnikov, N. N. Grib, Z. Ze, News Natl. Acad. Sci. Repub. Kaz., Ser. Geol. Tech. Sci., 2, 434, 39 (2019)

6. V. S. Imaev, L. P. Imaeva, O. P. Smekalin, B. M. Kozmin, N. N. Grib, A. V. Chipizubov, Geodyn. Tectonophys., 6, 3, 275 (2015)

7. V. R. Alekseev, Geodin. Tektonof., 6, 2, 171 (2015)

8. V. R. Alekseev Kriosfera Zemli, XXI, 6, 65 (2017)

9. V. R. Alekseev, Nauka, 263 (2005)

10. A. G. Topchiev, Obshcheros. Mat. Port. Math-Net.Ru. Specvypusk, 304 (2008)

11. A. V. Parshin, Vopr. Estestvozn., 2, 97 (2015)

12. V. V. Korotkov, N. A. Glinskij, V. N. Kirsanov, N. B. Kleper, A. V. Kuznecova, V. S. Cirel', Ross. Geofiz. ZH., 53-54, 122, (2014)

13. A. A. Syas'ko, N. N. Grib, V. S. Imaev, I. I. Kolodeznikov, A. V. Kachaev, GIAB, 12, 151 (2019)

14. A. A. Syasko, N. N. Grib, V. S. Imaev, L. P. Imaeva, I. I. Kolodeznikov, Geodyn. Tectonophys., 11, 1, 141 (2020)

15. J. Macnae, SEG Tech. Prog. Exp. Abs., 14, 375 (1995)

16. B. G. Zhang, Z. Q. Guo, L. Q. Zhu, Y. C. Qiao, GEM Beijing (2011) 
17. P. G. Martin, O. D. Payton, J. S. Fardoulis et al, J. Environ. Radioact., 143, 135, (2015)

18. M. Pirttyavi, Ryssänlampi magnetic survey using Radai UAV system and its comparison to airborne and ground magnetic data of GT: Detailed Survey Report, (2015)

19. B. Tezkan, R. Bergers, J. B. Stoll, U. Munch, Electromagnetic measurement method using unmanned aerial system: Research project AIDA (retrieved on 05/07/2019)

20. A. Wood, I. Cook, B. Doyle et al., Lead. Edge, 35, 3, 270 (2016) 